\title{
Electric and Spectroscopic Studies of Pulsed Corona Discharges in Nitrogen at Atmospheric Pressure
}

\author{
Alyen Abahazem ${ }^{1,2}$, Nofel Merbahi'2, Hasna Guedah', Mohammed Yousfi ${ }^{2}$ \\ ${ }^{1}$ Departement of Physics, LMER, Ibn Zohr University, Agadir, Morocco \\ ${ }^{2}$ LAPLACE, Université de Toulouse, CNRS, UPS, Toulouse, France \\ Email: alyenaba@yahoo.fr
}

How to cite this paper: Abahazem, A., Merbahi, N., Guedah, H. and Yousfi, M. (2017) Electric and Spectroscopic Studies of Pulsed Corona Discharges in Nitrogen at Atmospheric Pressure. Journal of Analytical Sciences, Methods and Instrumentation, 7, 57-74.

https://doi.org/10.4236/jasmi.2017.73006

Received: May 24, 2017

Accepted: July 21, 2017

Published: July 24, 2017

Copyright $\odot 2017$ by authors and Scientific Research Publishing Inc. This work is licensed under the Creative Commons Attribution International License (CC BY 4.0).

http://creativecommons.org/licenses/by/4.0/

\begin{abstract}
This paper is mainly dedicated to the experimental electric and spectroscopic analysis of positive corona discharges in the case of point to plane configuration, generated in nitrogen at atmospheric pressure. The maximum corona current (a few hundreds of $\mathrm{mA}$ ), the average current (a few $\mu \mathrm{A}$ ) and the average propagation velocity (a few $10^{7} \mathrm{~cm} / \mathrm{s}$ ) are analyzed with the variation of the applied voltage (a few $\mathrm{kV}$ ) and the gap distance (not exceeding $16 \mathrm{~mm}$ ). By using an ICCD camera, the dynamics of the discharge during the propagation of primary and secondary streamers across the gap distance was analyzed. Spectroscopic study is emphasized in a spectral range from $200 \mathrm{~nm}$ up to 500 $\mathrm{nm}$, to determine the important excited species present in the gaseous environment such as the second positive and the first negative systems (SPS and FNS respectively). The identification of the quenching $\mathrm{NO}_{\gamma}$ emission bands is also emphasized.
\end{abstract}

\section{Keywords}

Corona Discharge, Nitrogen, Atmospheric Pressure, Spectroscopic Study, ICCD Camera

\section{Introduction}

Corona discharges created under a pulsed voltage, have been studied as a potential technology for the removal of dangerous environmental pollutant [1] [2] [3] and appear to offer a specific advantage for gas treatment with a big efficiency [4]. The corona discharges created under a pulsed voltage, produce the streamers, in which many types of radicals, ions and excited particles are produced by 
electron impact process. The chemical species produced in the streamers transform the pollutant molecules by chemical reactions. The plasma generated by pulsed corona discharge processes, breeds in several stages. In the beginning, when we apply a positive high voltage to a point-to-plan gap, an avalanche phenomenon builds up. Then, when the space charges begin to affect the applied field, the streamer discharges create a faintly ionized channel, and a small luminous zone, "steamer head" develops from the anode towards the cathode. The streamer head reaches the plane in a few tens of nanoseconds and creates an ionized filament that links the point and the plane. This primary phase called "primary streamer" [5] [6]. After the primary streamer reaches the cathode, a following streamer develops from the point towards the plane up to the half of the gap between electrodes. That is called a "secondary streamer" [5] [6].

Several studies of corona discharge ignited in nitrogen by the pulsed voltage at atmospheric pressure were carried out to provide more detailed on the discharge behavior and breakdown mechanisms [7] [8] [9] [10] [11]. Furthermore, $\mathrm{N}_{2}$ is also chosen because it's the dominant gas of ambient air in the atmosphere and is broadly used in many industrial and technical applications as for instance plasma nitriding and surface treatments.

The present work is dedicated to spectroscopic and parametric studies of pulsed corona discharge ignited in nitrogen between point to plan configuration. The objective is to study the influence of various parameters like: inter-electrode distance and the magnitude of high voltage on the maximum corona current, average current and the propagation velocity of streamers.

We limited ourselves to the regime of pulsed voltage because under our experimental conditions under DC power supply the streamer regime is not stable because we get directly a transition from glow or onset streamer to spark regime, which are not studied in this work. The means used to record our measurement are those that we used in our previous work [12]. Then we give a different images recorded by an ICCD camera to see the development of the discharge in the inter-electrode space, showing different instants corresponding to the propagation of streamers in the gap distance. Excited species present in the gaseous medium were also observed by using spectroscopic investigations.

\section{Experimental Arrangements}

Schematic overview of our measurement set-up that we have already referred in our previous work [12] [13] is given in Figure 1. Corona discharges are generated under a positive pulsed high voltage, by using point plane arrangement in a sealed cell at atmospheric pressure. The point is made of tungsten. And its curvature radius, $\rho$, is around $20 \mu \mathrm{m}$. A disc of copper of $2 \mathrm{~cm}$ of thickness was used as a cathode. The two electrodes are separated by an inter-electrode distance adjustable from the outside by means of a $\mathrm{Z}$ column, without opening the reactor. The purge of the reactor is carried out by the combination of two pumps which make it possible to obtain a secondary vacuum, a primary pump and a secondary 


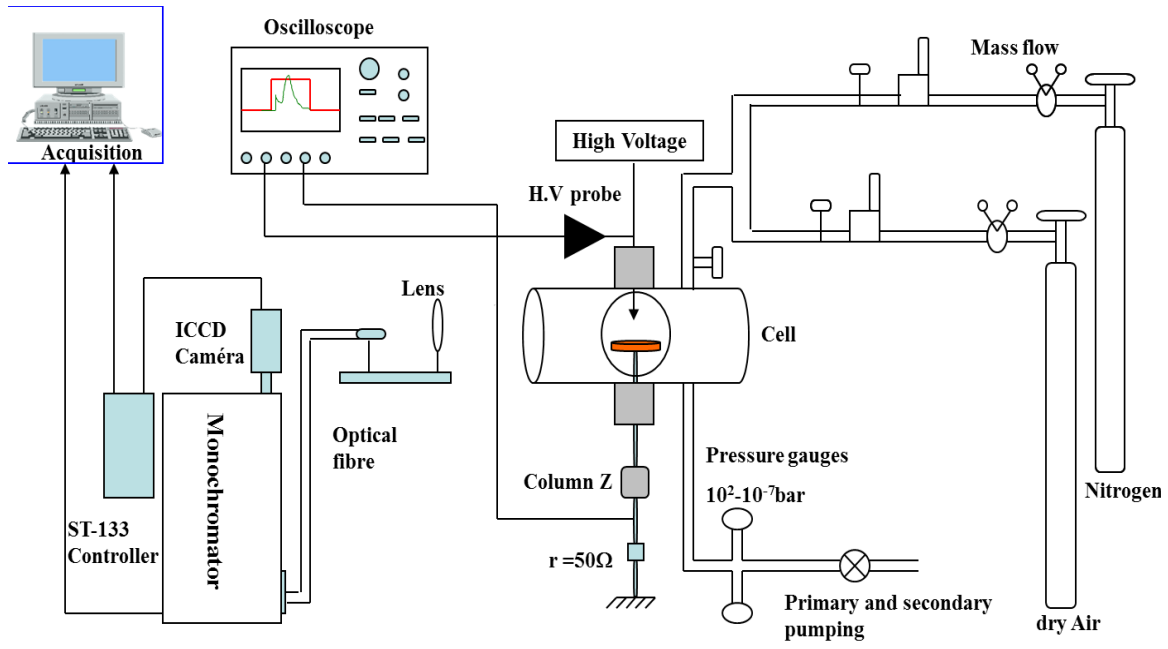

Figure 1. Schematic diagram of the experimental device.

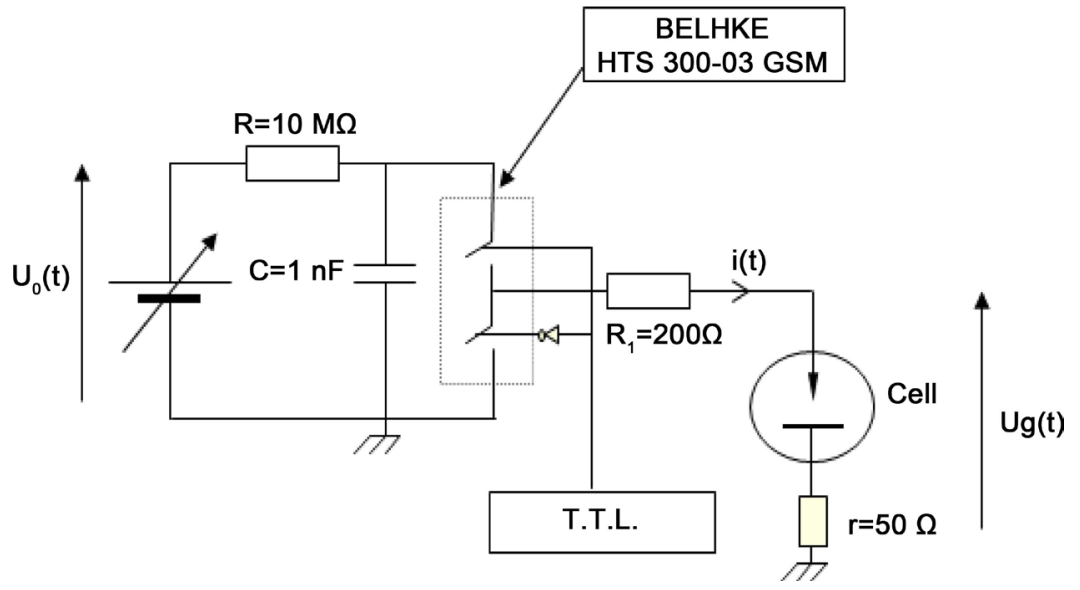

Figure 2. Electric circuit of the pulsed power supply.

pump which is a turbo-molecular pump. The discharge is generated by using a pulsed high-voltage supply.

The pulse voltage supply diagram (Figure 2 ) is composed by a DC high voltage (up to $15 \mathrm{kV}$ ) which is subsequently transformed in a pulsed voltage by the Behlke switch (HTS 300-03 GSM) controlled by a TTL which can adjust the frequency and the pulse width of the applied voltage. The maximum frequency that can be reached is of $100 \mathrm{~Hz}$ and the voltage width, $\tau$, is from $10 \mu$ s to $500 \mu$ s. The switch is connected to the chamber of corona discharge, which is in series with a resistor $r$ to measure the current of the discharge $i(t)$. The waveforms are recorded through an oscilloscope (sampling frequency of $5 \mathrm{G} \cdot \mathrm{s}^{-1}$ and $500 \mathrm{MHz}$ of bandwidth) while the mean current of the discharge is measured by a digital ammeter.

The emitted light by plasma is focused by a lens on an optical fiber. The latter is connected to a monochromator in which the light is dispersed by a diffraction grating and detected by a CCD sensor.

The monochromator has a focal length of $0.5 \mathrm{~m}$ (2500i SpectraPro Acton Re- 
search Corporation) and equipped with a set of three diffraction gratings (600, 1200 and 2400 grooves $\cdot \mathrm{mm}^{-1}$ ) to analyze the emitted light from the discharge. It has an output port with an ICCD camera (PI-MAX, Princeton Instruments) for continuously spectral measurements.

\section{Results and Discussion}

The electrical study presented in this part, concerns mainly the variation of the inter-electrode distance and the pulsed applied voltage, to understand the influence of our parameters on the behavior of the corona discharge obtained in nitrogen. The objective is to analyze their influences on the maximum corona discharge current, the streamer velocity and the average corona current. Then the imagery analysis by ICCD camera will complete the electrical study to visualize the development of the discharge in the inter-electrode space and also to support the analysis that will be given in this section. The spectroscopic study of corona discharge, in the wavelength domain from $200 \mathrm{~nm}$ to $500 \mathrm{~nm}$ is also carried out.

\subsection{Electrical Study of Corona Discharge in Tip to Plane Configuration}

The pulse shape of the pulsed applied voltage and the corona current discharge is shown in Figure 3, for a frequency of $100 \mathrm{~Hz}$, pulse width of the voltage of 40 $\mu$, inter-electrode distance of $8 \mathrm{~mm}$ and applied voltage of $8 \mathrm{kV}$ in pure nitrogen case at atmospheric pressure.

As we have seen in the previous paper [12], we mention the presence of several peaks in the pulse current. First and last peak (opposite sign), superposes with the rising and lowering phase of the applied voltage pulse. These are therefore the capacitive currents created by the rapid change of the applied voltage on the

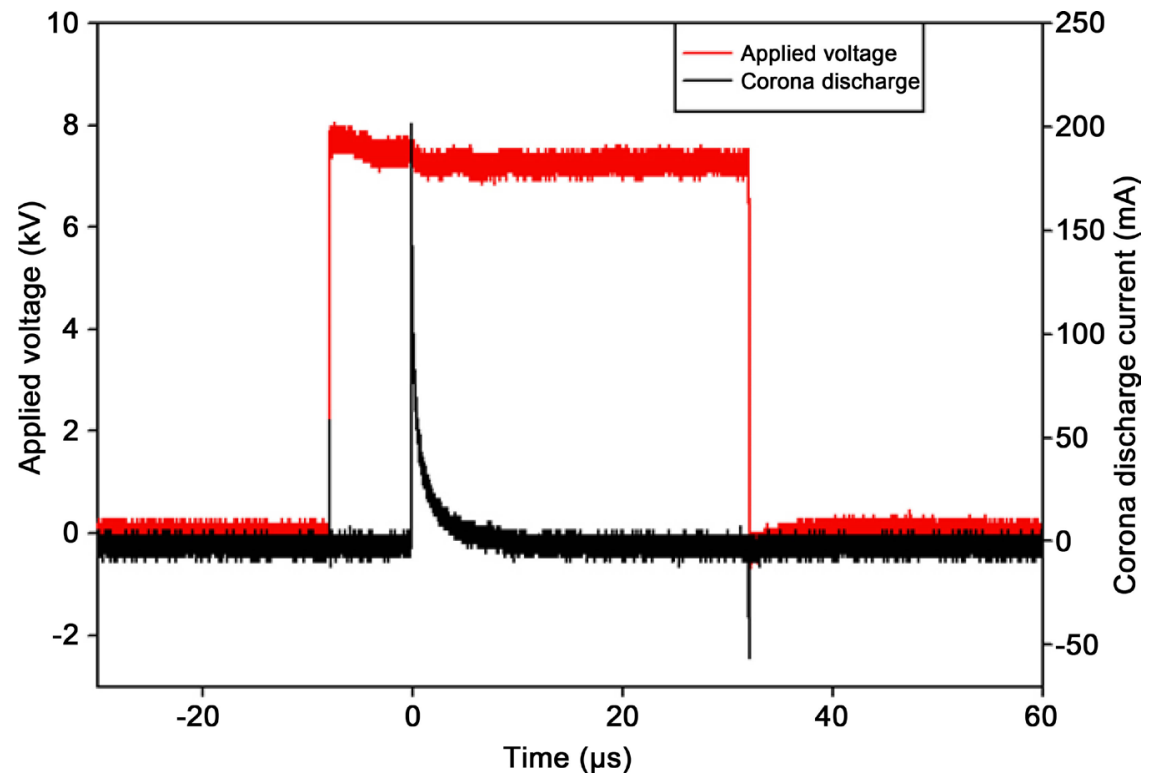

Figure 3. Corona current and applied voltage for $\mathrm{d}=8 \mathrm{~mm}, \mathrm{f}=100 \mathrm{~Hz}, \mathrm{~V}_{\mathrm{a}}=8 \mathrm{kV}$ and $\tau$ $=40 \mu \mathrm{s}$ in pure nitrogen. 


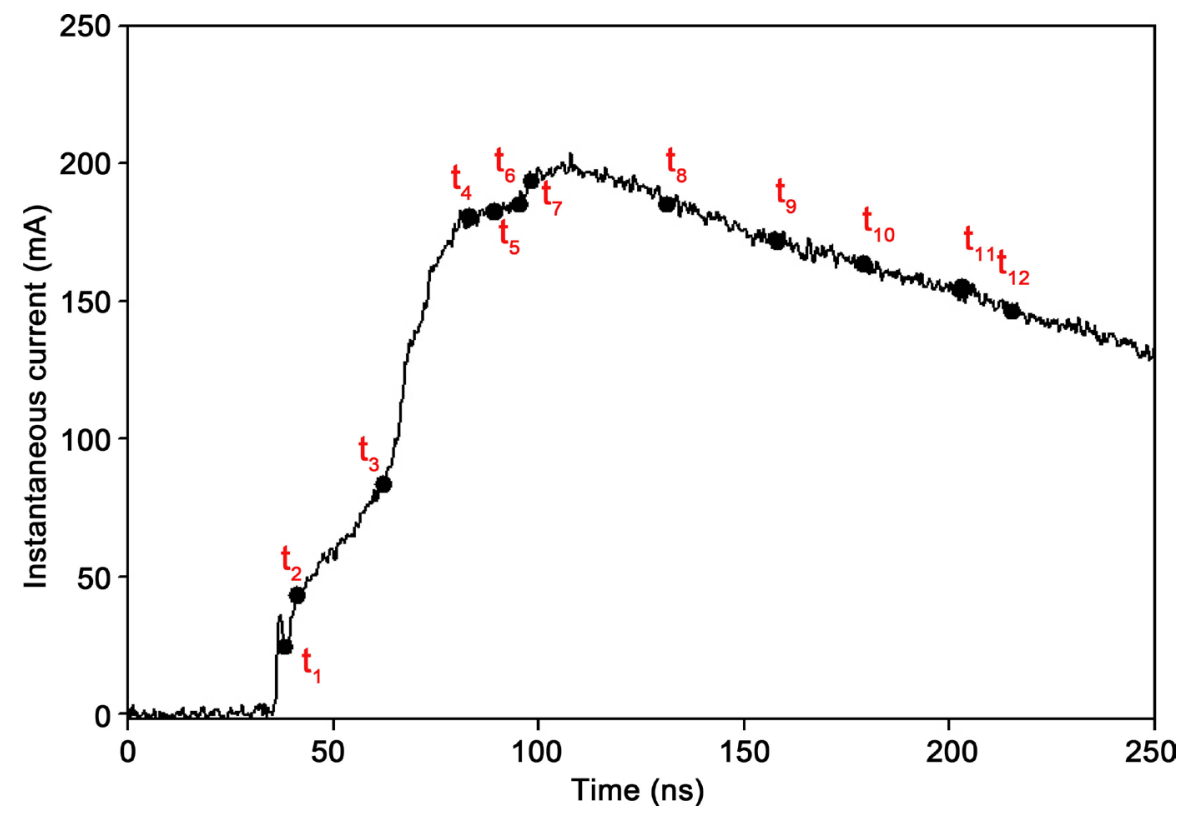

Figure 4. Instantaneous corona discharge current in pure nitrogen for $\mathrm{d}=8 \mathrm{~mm}, \mathrm{f}=100$ $\mathrm{Hz}, \mathrm{V}_{\mathrm{a}}=8 \mathrm{kV}$ and $\tau=40 \mu \mathrm{s}$.

tip. However, the central peak (or second peak) is the corona discharge current. We are interested in this work by its variation with our various operating parameters. Our analysis relates more particularly to the influence of different parameters on the instantaneous and average current of the discharge. A zoom of the corona discharge, is shown in Figure 4.

Along with the discharge current, we also analyze the snapshot images recorded by the ICCD camera. Figure 5 shows the images taken every 3 ns, the instants $t_{\mathrm{i}}$ of images are directly indicated on the curve of the discharge current (Figure 4).

The beginning of the discharge is marked by the presence of the space charge peak (first very narrow peak shown in Figure 4), with a duration of 3 ns and intensity of $36 \mathrm{~mA}$. This space charge current appears very early in comparison with the result obtained in dry air [12], because of the absence of the attachment process in the pure nitrogen case. The critical size of the avalanche that allows the propagation of the streamer corona is reached very quickly in the case of nitrogen ( $3 \mathrm{~ns}$ under our experimental conditions). It is represented by the snapshot at instant $t_{1}=3 \mathrm{~ns}$ in Figure 5. At the end of this phase, several streamers propagate simultaneously from the tip towards the plane and through the inter-electrode space with different speeds ( $t_{2}$ and $t_{3}$ in Figure 4 and 6 ns and $27 \mathrm{~ns}$ in Figure 5). After $t_{3}$, we observe a change in the slope (Figure 4), this reflects the sharp increase of the streamer propagation velocity just before their arrival on the plane.

The average streamer propagation velocity is estimated to about $2.63 \times 10^{7}$ $\mathrm{cm} / \mathrm{s}$. The instants $t_{4}, t_{5}, t_{6}$ and $t_{7}$ (Figure 4) correspond to the coming of the streamers on the plane (snapshots at 48 ns, 54 ns, 60 ns and 63 ns of Figure 5). 


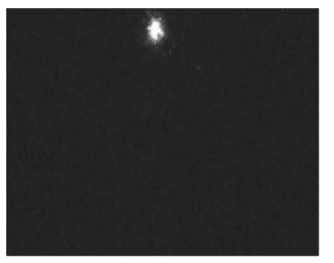

$t_{1}=3 n s$

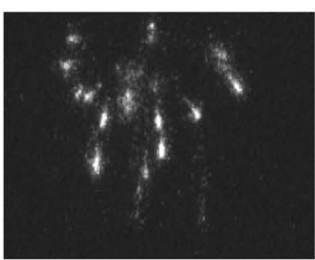

$t_{4}=48 n s$

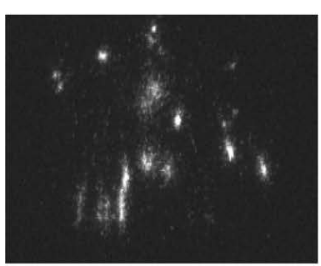

$t_{7}=63 \mathrm{~ns}$

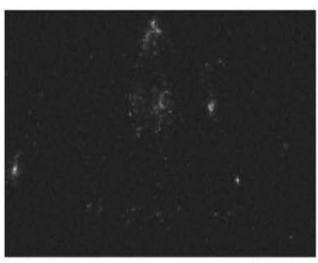

$t_{10}=144 \mathrm{~ns}$

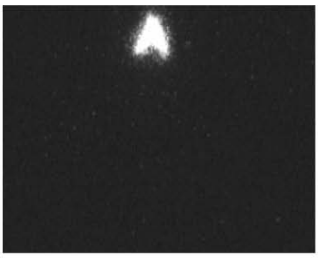

$t_{2}=6 n s$

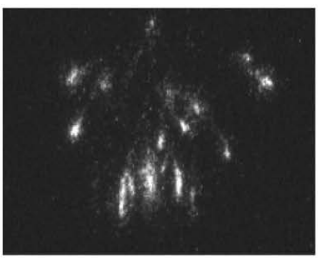

$t_{5}=54 s$

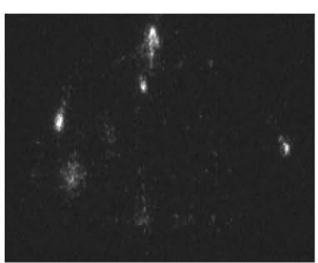

$t_{8}=96 n s$

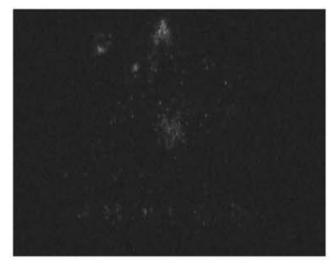

$\mathrm{t}_{11}=168 \mathrm{~ns}$

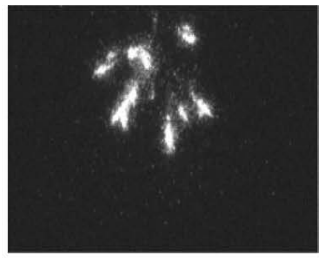

$t_{3}=27 n s$

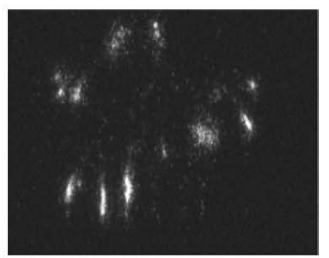

$t_{6}=60 \mathrm{~ns}$

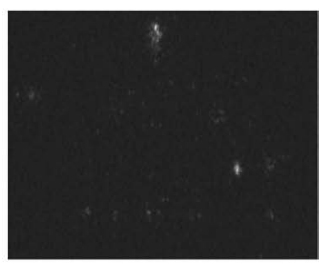

$t_{9}=123 n s$

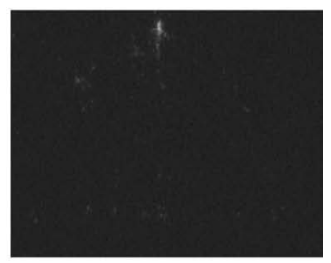

$t_{12}=180 \mathrm{~ns}$

Figure 5. Images at different instants of evolution of the discharge at atmospheric pressure in pure nitrogen for $\mathrm{d}=8 \mathrm{~mm}, \mathrm{f}=100 \mathrm{~Hz}, \mathrm{~V}_{\mathrm{a}}=8 \mathrm{kV}$ and $\tau=40 \mu \mathrm{s}$, exposure time of $3 \mathrm{~ns}$ and the reference intensity image is $123 \mathrm{~ns}$.

The images taken respectively at $96 \mathrm{~ns}, 123 \mathrm{~ns}$ and $144 \mathrm{~ns}$, correspond to the propagation of secondary streamers start from the tip, but without exceeding the half of the inter-electrode space. The part corresponding to the beginning of the current relaxation is illustrated by the images taken at the instants $168 \mathrm{~ns}$ and $180 \mathrm{~ns}$ in Figure 5. As expected, we observe that the relaxation phase is much less luminous because of the presence of lower energy electrons.

\subsubsection{Influence of Gap Distance and Applied Voltage on Maximum Corona Current}

The variation of the maximum corona current discharge (second peak on Figure 4) with the inter-electrode distance for different applied voltages is shown in Figure 6.

For a fixed applied voltage, pulse width of the voltage and frequency, the maximum corona discharge current decreases with the inter-electrode distance (see Figure 6). This is simply due to the lowering of the electric field versus the gap space [10] [12] [14], which subsequently lower the energy and the ionizing 


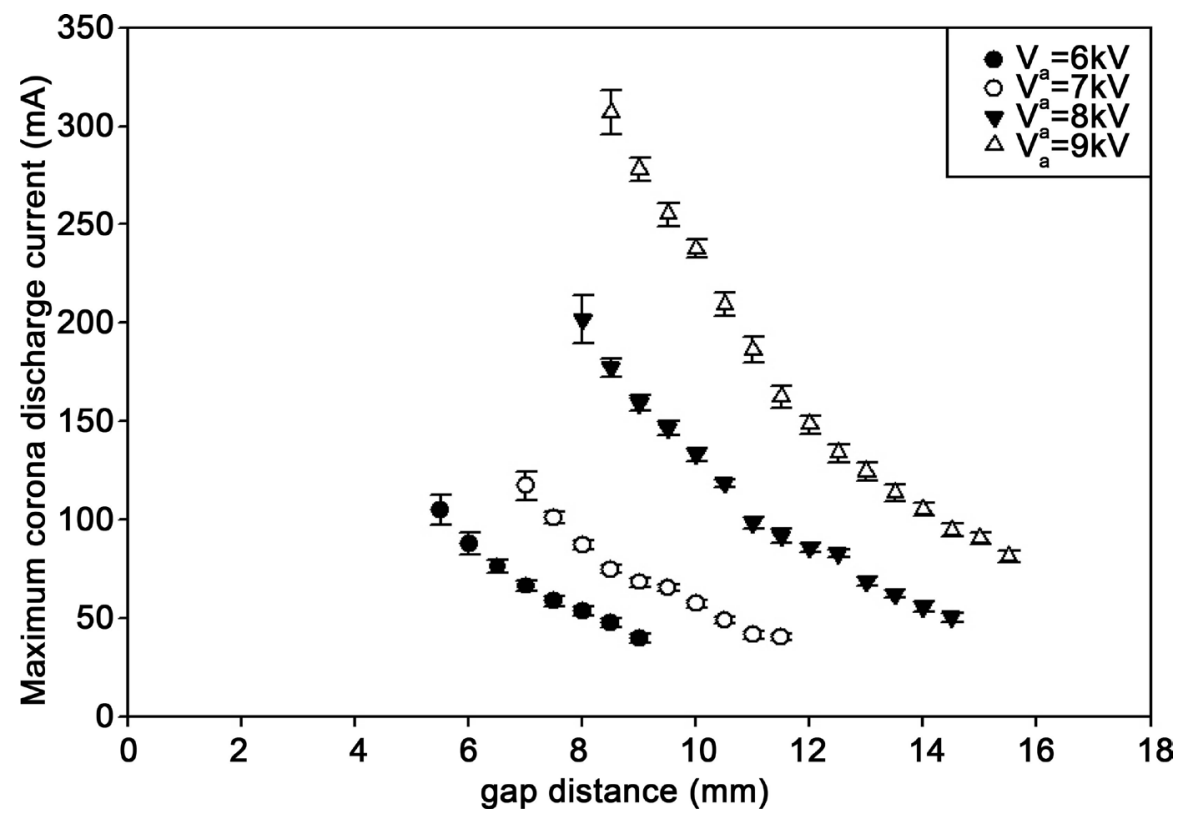

Figure 6. Maximum corona discharge current with gap distance for different applied voltage in pure nitrogen for, $\tau=40 \mu$ s and $\mathrm{f}=100 \mathrm{~Hz}$.

efficiency of the electrons. However, for a given gap distance, the maximum current of the corona discharge increases as expected when the applied voltage rises because the electron energy and the ionization efficiency increases when a higher voltage is applied. This is directly reflected in an enhancement of the charged particle convection and the maximum discharge current [15].

\subsubsection{Average Velocity of Primary Streamer Propagation}

The average primary streamer propagation velocity is calculated from the current of corona discharge (Figure 4) by dividing the gap distance on the time flowing of the primary streamer through the gap [13] [16]. The traverse time of the primary streamer from the point to the plane, is estimated from the current pulse plotted in Figure 4. The propagation streamer time begins at the rise of the first current peak (at $35 \mathrm{~ns}$ in this case) and ends at the beginning of the change of the slope of the second peak (after the instant $t_{3}$ ). The variation of the average propagation velocity, with the inter electrode distance, for different applied voltages is shown on Figure 7. For a given voltage, the propagation velocity decreases with rising the inter electrode distance, because the electric field in the gap inter electrode becomes lower. However, for a fixed interelectrode distance, the average propagation velocity increases as expected when the applied voltage is risen [14] [17]-[24].

The results of the literature for the steamers propagation velocity at atmospheric pressure in the nitrogen are fairly consistent with ours when considering the field magnitude orders at the streamers head. For example, Bayle et al. [25] have measured the variation of the propagation velocity of the streamer in nitrogen. They obtained variations between 2 and $4 \times 10^{8} \mathrm{~cm} \cdot \mathrm{s}^{-1}$ in a range of the electric field to pressure ratio E/P from 155 to $1850 \mathrm{~V} \cdot \mathrm{cm}^{-1} \cdot \mathrm{Torr}^{-1}$ (about $470 \mathrm{Td}$ 


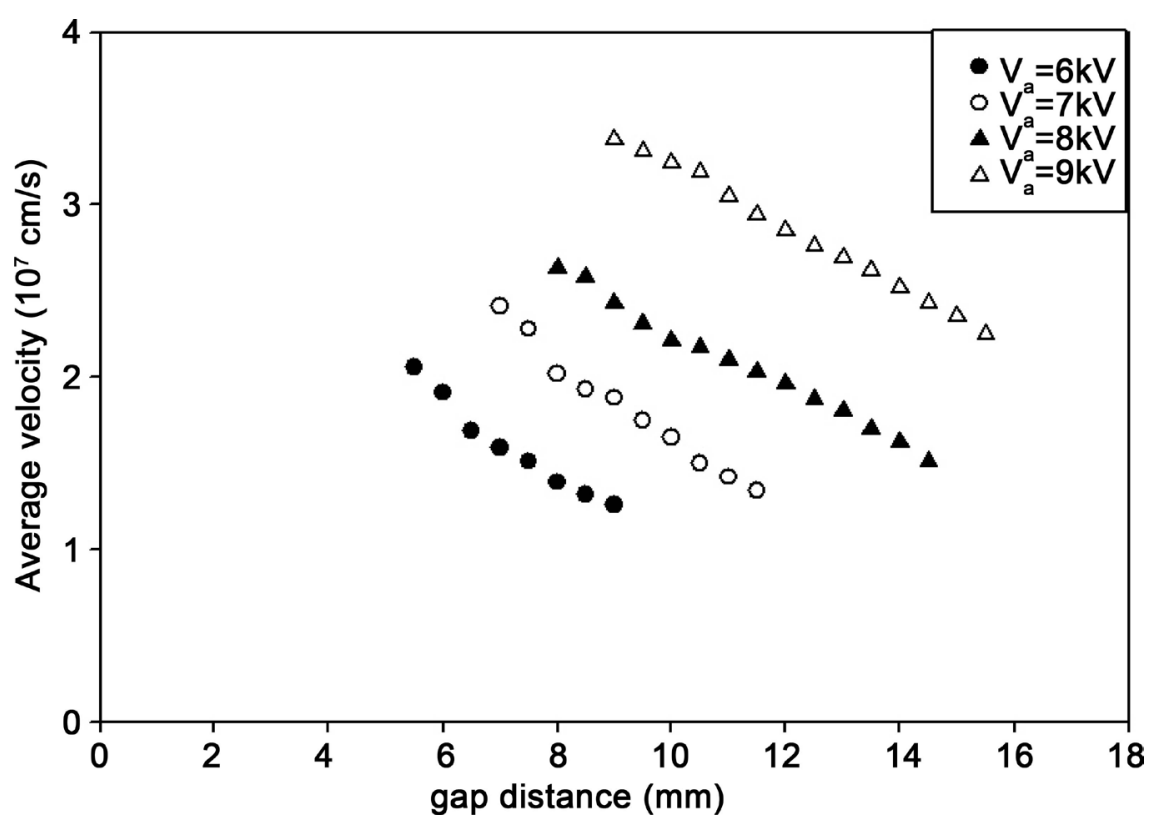

Figure 7. Average propagation velocity with the gap distance for different applied voltage in pure nitrogen for $\mathrm{f}=100 \mathrm{~Hz}$ and $\tau=40 \mu \mathrm{s}$.

and $560 \mathrm{Td}$ ). While, Chalmers et al. [26], have obtained streamer propagation velocities between 1 and $6 \times 10^{7} \mathrm{~cm} / \mathrm{s}$, for the smaller E/P variations, between 45 and $55 \mathrm{~V} \cdot \mathrm{cm}^{-1} \cdot$ Torr $^{-1}$ (between $136 \mathrm{Td}$ and $167 \mathrm{Td}$ ). Stritzke et al. [27], have published the results for $\mathrm{E} / \mathrm{P}=50 \mathrm{~V} \cdot \mathrm{cm}^{-1} \cdot$ Torr $^{-1}$ (about $150 \mathrm{Td}$ ) which are of the order of $5 \times 10^{7} \mathrm{~cm} \cdot \mathrm{s}^{-1}$. Whereas, Naidis [28] has analytically shown a relationship between the average primary streamer propagation velocity, the diameter and a primary streamer head reduced electric field E/N. This relationship has been used by Atsushi Komuro et al. [29] to explain the decrease of the pulsed voltage, leading to the decrease of the current and velocity of the primary streamer.

\subsubsection{Influence of Gap Distance and Applied Voltage on the Average Current of Corona Discharge}

The variation of the average discharge current with the inter electrode distance, for different applied voltage, a given pulse duration and frequency are shown in Figure 8. We observe, as expected, when the voltage growing up the average discharge current rises (for fixed gap distance, frequency and pulse duration). Also, for a given applied voltage, pulse duration and frequency the mean current discharge decreases when the gap distances increase [13]. For each applied voltage, the minimal distance is the distance just before to switch into the spark regime and the larger distance corresponds to the last detectable or measurable current. In this study, we were interested to the corona discharge regime, just before going to the spark regime.

If we fix the applied voltage at a given value of $7 \mathrm{kV}$, the average corona current discharge decreases when we increase the inter electrode distances from 7 $\mathrm{mm}$ to $11.5 \mathrm{~mm}$. This variation range matches to the appearance of the maxi- 


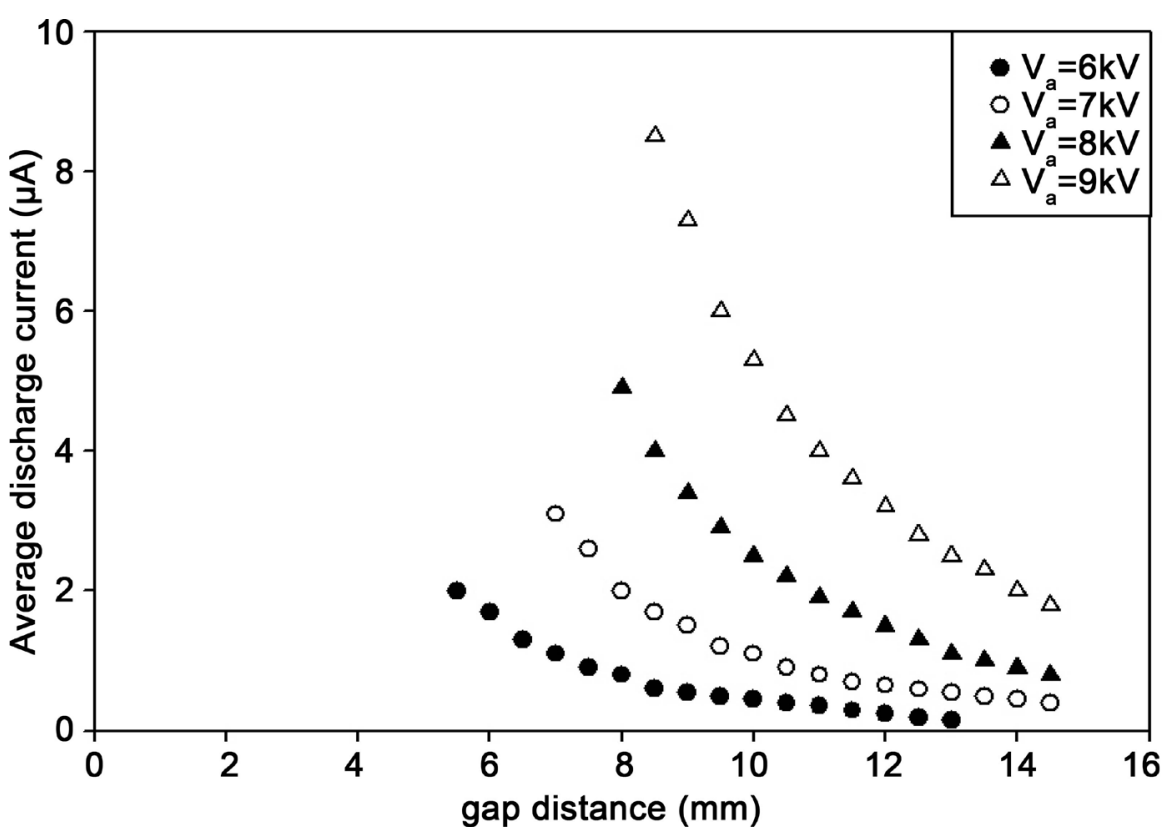

Figure 8. Average discharge current with the inter electrode distance in pure nitrogen for several applied voltage, $\tau=40 \mu$ s and $\mathrm{f}=100 \mathrm{~Hz}$.

mum corona current discharge. Conversely, the average discharge current decreases linearly between $11.5 \mathrm{~mm}$ and $14.5 \mathrm{~mm}$, without observing a corona discharge current in this range (Figure 8). This current is due to the convective flow of particles generated in the inter-electrode space which is registered and persists even outside of the streamer corona discharge regime (glow or pre-onset streamer regime). We observe the same trends for the other applied voltages.

\subsection{Spectroscopic Investigation of Corona Discharge}

The purpose is to identify the main excited species present in the gaseous medium, in the pulsed positive tip to plane discharge at atmospheric pressure in pure nitrogen.

It is notable that, the variation of the operating parameters considered above leads to qualitatively equivalent emission spectra. Only the spectra intensity can change during for instance the increase of the voltage or the decrease the gap distance. Therefore, we give in the following the emission spectra only for one case matching to an inter electrode distance of $8 \mathrm{~mm}$, a maximum voltage of 8 $\mathrm{kV}$, a frequency of $100 \mathrm{~Hz}$ and pulse width of $40 \mu \mathrm{s}$. The spectra were logged in the wavelength domain from $200 \mathrm{~nm}$ to $500 \mathrm{~nm}$ by using a grating of 2400 grooves $/ \mathrm{mm}$.

\subsubsection{Emission of $N_{2}\left(C^{3} \pi_{u}-B^{3} \pi_{g}\right)$ and $N_{2}^{+}\left(B^{2} \Sigma_{u}^{+}-X^{2} \Sigma_{g}^{+}\right)$}

Figure 9 shows the different emissions recorded in the corona discharge produced in pure nitrogen at atmospheric pressure under pulsed voltage regime within $200 \mathrm{~nm}$ and $500 \mathrm{~nm}$. We observe the presence of nitrogen second positive system (SPS: $\mathrm{N}_{2}\left(\mathrm{C}^{3} \pi_{\mathrm{u}}-\mathrm{B}^{3} \pi_{\mathrm{g}}\right)$ ), characterized by higher intensities. This one cov- 


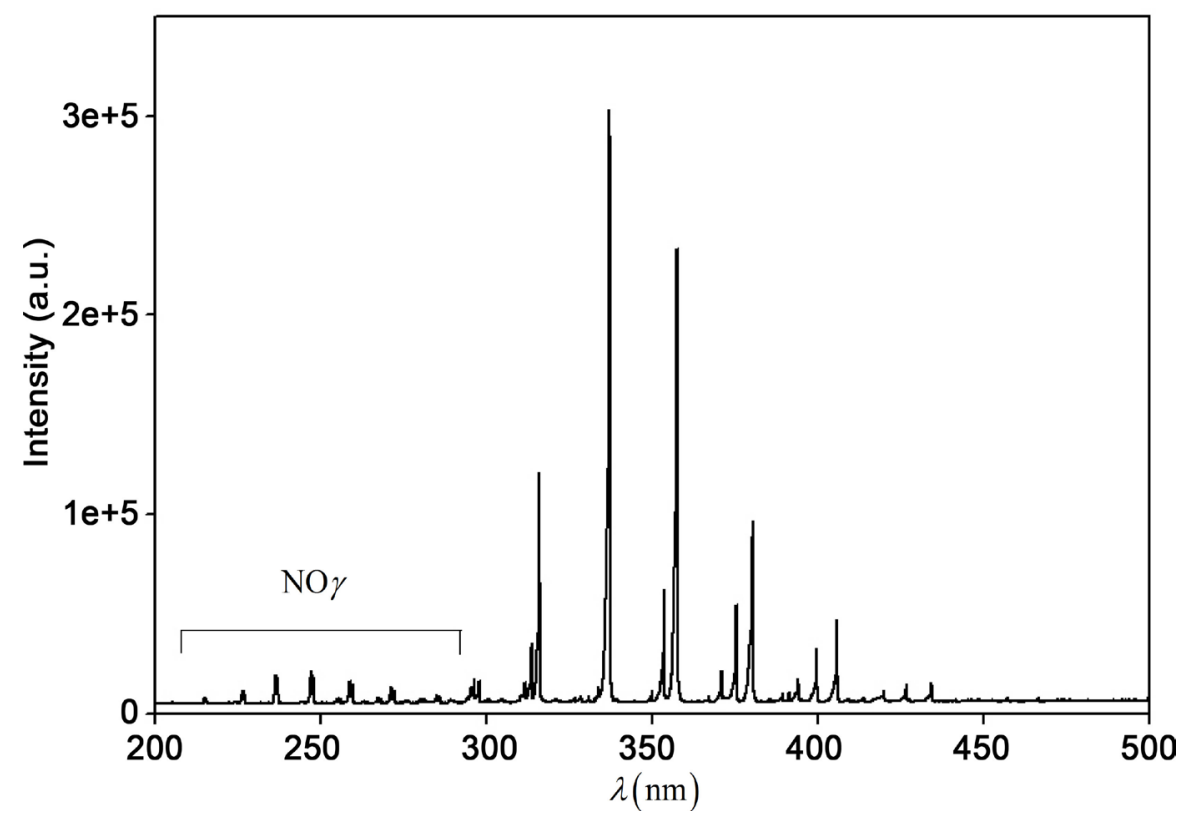

Figure 9. Emission spectrum of corona discharge in pure nitrogen for $\mathrm{d}=8 \mathrm{~mm}, \mathrm{~V}_{\mathrm{a}}=8$ $\mathrm{kV}, \mathrm{f}=100 \mathrm{~Hz}, \tau=40 \mu \mathrm{s}$, exposure time: $1 \mathrm{~s}$ and grating: 2400 grooves $/ \mathrm{mm}$.

ers the spectral range from $295.32 \mathrm{~nm}$ to $434.36 \mathrm{~nm}$. This system is compounded by seven series of emission bands: $\Delta v=+2$ and $+1, \Delta v=0$ and $\Delta v=-1,-2,-3$, -4 , (the emission recorded at the wavelength $337 \mathrm{~nm}$, for the transition $(0,0)$ corresponds to the most intense SPS emission, observed in this spectrum). We note also the presence of one emission at $391.44 \mathrm{~nm}$, very low light intensity, corresponding to nitrogen first negative system (FNS: $\mathrm{N}_{2}^{+}\left(\mathrm{B}^{2} \Sigma_{\mathrm{u}}^{+}-\mathrm{X}^{2} \Sigma_{\mathrm{g}}^{+}\right)$. This system is composed only by one emission band series with $\Delta v=0$ (Figure 9).

Figure 10 displays a zoom of the different head bands of $\mathrm{N}_{2}\left(\mathrm{C}^{3} \pi_{\mathrm{u}}-\mathrm{B}^{3} \pi_{\mathrm{g}}\right)$ and $\mathrm{N}_{2}^{+}\left(\mathrm{B}^{2} \Sigma_{\mathrm{u}}^{+}-\mathrm{X}^{2} \Sigma_{\mathrm{g}}^{+}\right)$.

\subsubsection{Emission of the $\mathrm{NO}_{\gamma}\left(\mathrm{A}^{2} \Sigma^{+}-\mathrm{X}^{2} \Pi\right)$ System}

In Figure 9, we have also observed the presence of much less intense emissions, corresponding to the $\mathrm{NO}$ emissions ( $\mathrm{O}$ coming from the impurities present in our nitrogen) and more particularly $\mathrm{NO}_{\gamma}\left(\mathrm{A}^{2} \Sigma^{+}-\mathrm{X}^{2} \Pi\right)$ emissions, which covers the wavelength range from $214.9 \mathrm{~nm}$ to $289.8 \mathrm{~nm}$. In general we get eight emission bands series, including one transition corresponding to $\Delta v>0$, one transition corresponding to $\Delta v=0$ and six transition corresponding to $\Delta v<0$. Figure 11 shows a zoom of the different head bands of $\mathrm{NO}_{\gamma}$ system, observed in Figure 9.

\subsubsection{Discussions}

The excitation of the $\mathrm{N}_{2}$ molecule occurs during the primary streamer propagation and secondary streamer propagation phase. During this phase, ionization, excitation and recombination, are the main reactions. If the electrons are sufficiently energetic, the ionization occurs from the ground state $\mathrm{N}_{2}\left(\mathrm{X}^{1} \Sigma_{\mathrm{g}}^{+}, v\right)$ molecule as following: 


$$
\begin{array}{lll}
\mathrm{e}^{-}+\mathrm{N}_{2}\left(\mathrm{X}^{1} \Sigma_{\mathrm{g}}^{+}, v\right) \rightarrow \mathrm{N}_{2}^{+}\left(\mathrm{X}^{2} \Sigma_{\mathrm{g}}^{+}, v^{\prime}\right)+2 \mathrm{e}^{-} \quad(\Delta \mathrm{E} 15.5 \mathrm{eV}) & \mathrm{R} 1 \\
\mathrm{e}^{-}+\mathrm{N}_{2}\left(\mathrm{X}^{1} \Sigma_{\mathrm{g}}^{+}, v\right) \rightarrow \mathrm{N}_{2}^{+}\left(\mathrm{B}^{2} \Sigma_{\mathrm{u}}^{+}, v^{\prime}\right)+2 \mathrm{e}^{-} \quad(\Delta \mathrm{E} 19 \mathrm{eV}) & \mathrm{R} 2 \\
\mathrm{e}^{-}+\mathrm{N}_{2}\left(\mathrm{X}^{1} \Sigma_{\mathrm{g}}^{+}, v\right) \rightarrow \mathrm{N}_{2}^{+}\left(\mathrm{C}^{2} \Sigma_{\mathrm{g}}^{+}, v^{\prime}\right)+2 \mathrm{e}^{-} \quad(\Delta \mathrm{E} 23.5 \mathrm{eV}) & \mathrm{R} 3
\end{array}
$$

Naturally, there are also the direct excitations by electronic impact from the ground states which require less energy than the ionization [30]:

$$
\begin{array}{lll}
\mathrm{e}^{-}+\mathrm{N}_{2}\left(\mathrm{X}^{1} \Sigma_{\mathrm{g}}^{+}, v\right) \rightarrow \mathrm{N}_{2}\left(\mathrm{~A}^{3} \Sigma_{\mathrm{u}}^{+}, v^{\prime}\right)+\mathrm{e}^{-} \quad(\Delta \mathrm{E} 6-7 \mathrm{eV}) & \mathrm{R} 4 \\
\mathrm{e}^{-}+\mathrm{N}_{2}\left(\mathrm{X}^{1} \Sigma_{\mathrm{g}}^{+}, v\right) \rightarrow \mathrm{N}_{2}\left(\mathrm{~B}^{3} \pi_{\mathrm{g}}, v^{\prime}\right)+\mathrm{e}^{-} \quad(\Delta \mathrm{E} 7.5-8 \mathrm{eV}) & \mathrm{R} 5 \\
\mathrm{e}^{-}+\mathrm{N}_{2}\left(\mathrm{X}^{1} \Sigma_{\mathrm{g}}^{+}, v\right) \rightarrow \mathrm{N}_{2}\left(\mathrm{C}^{3} \pi_{\mathrm{u}}, v^{\prime}\right)+\mathrm{e}^{-} \quad(\Delta \mathrm{E} 11-12 \mathrm{eV}) & \mathrm{R} 6
\end{array}
$$
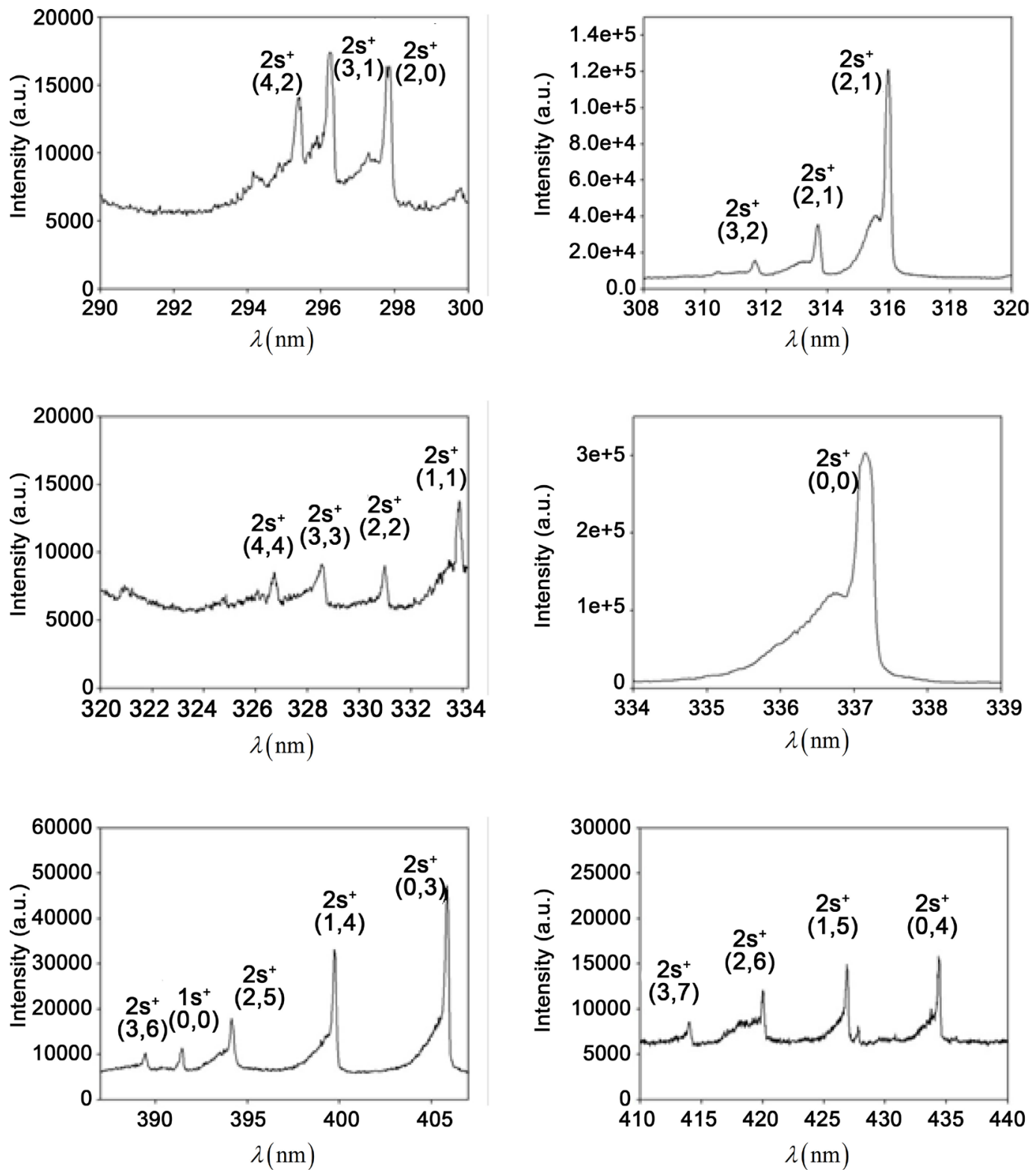

Figure 10. Spectra of different transitions of nitrogen second positive system and first negative system in pure nitrogen for $\mathrm{d}=8 \mathrm{~mm}, \mathrm{~V}_{\mathrm{a}}=8 \mathrm{kV}, \mathrm{f}=100 \mathrm{~Hz}$ and $\tau=40 \mu \mathrm{s}$. 

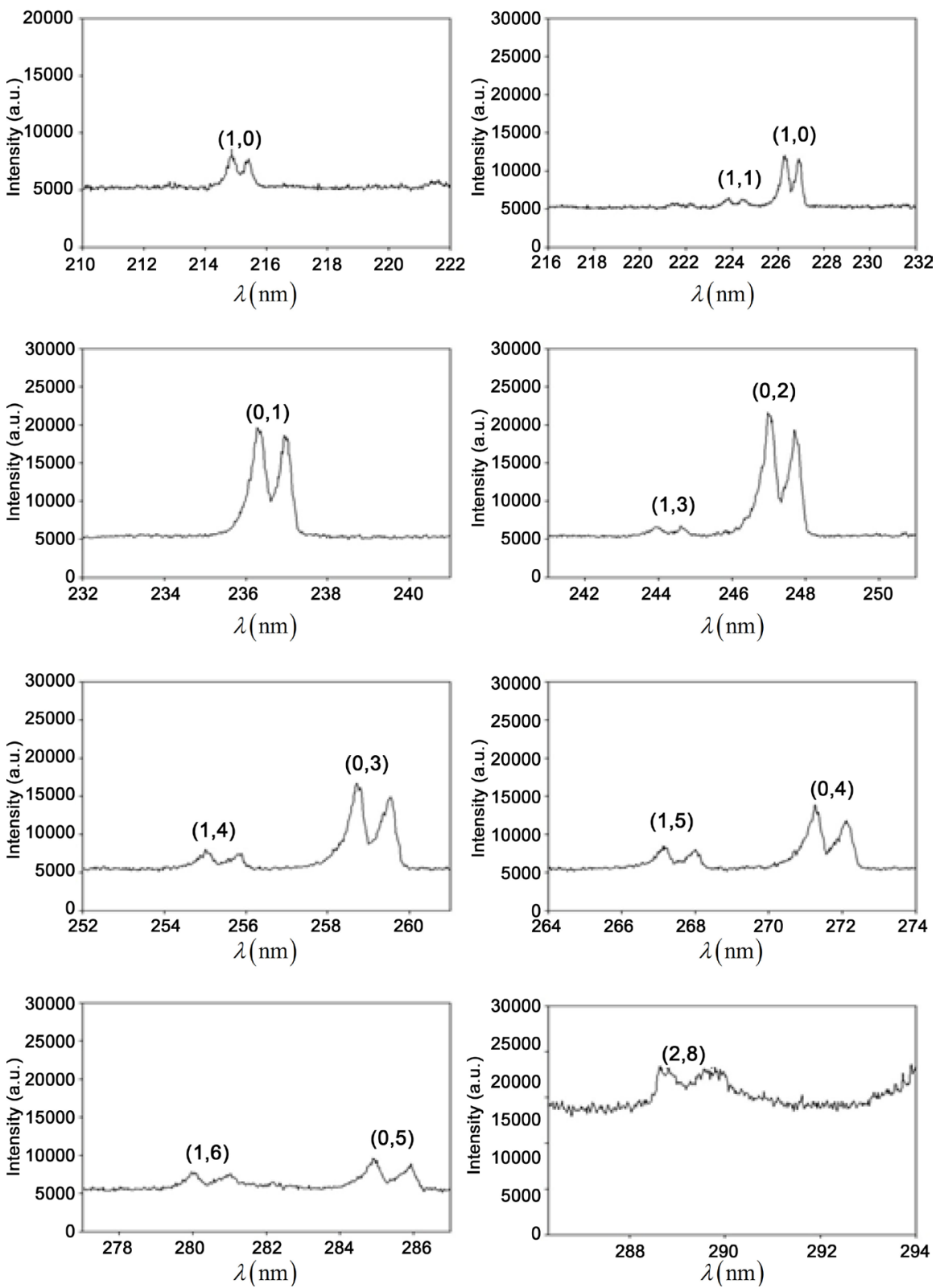

Figure 11. Zoom on different transitions of $\mathrm{NO}_{\gamma}$ system in pure nitrogen for $\mathrm{d}=8 \mathrm{~mm}, \mathrm{f}$ $=100 \mathrm{~Hz}, \mathrm{~V}_{\mathrm{a}}=8 \mathrm{kV}$ and $\tau=40 \mu \mathrm{s}$.

There may also have an over-excitation due to the interactions of excited molecules with one electron but that is much less likely than the direct excitation owing to the weakly ionized nature of the generated plasma in the corona discharge. The reason is easy to understand because, even if the cross section of over-excitation of a molecule is greater than one order of magnitude as that the excitation from the fundamental, the density of the excited states is smaller of about $10^{5}$ times, whence the product density times the cross section is clearly an advantage of the process from the fundamental level (approximately greater by $10^{4}$ times). We will not discuss here the electronic excitation or the stepwise ionization involving the metastable state $\mathrm{N}_{2}\left(\mathrm{~A}^{3} \Sigma_{\mathrm{u}}^{+}, v^{\prime}\right)$, because of its long life- 
time, about $13 \mathrm{~s}$ [31].

- The excitation from the metastable state $\mathrm{N}_{2}\left(\mathrm{~A}^{3} \Sigma_{\mathrm{u}}^{+}, v^{\prime}\right)$ :

$$
\begin{aligned}
\mathrm{e}^{-}+\mathrm{N}_{2}\left(\mathrm{~A}^{3} \Sigma_{\mathrm{u}}^{+}, v^{\prime}\right) \rightarrow \mathrm{N}_{2}\left(\mathrm{~B}^{3} \pi_{\mathrm{g}}, v^{\prime \prime}\right)+\mathrm{e}^{-} & (\Delta \mathrm{E} 1-2 \mathrm{eV}) \\
\mathrm{e}^{-}+\mathrm{N}_{2}\left(\mathrm{~A}^{3} \Sigma_{\mathrm{u}}^{+}, v^{\prime}\right) \rightarrow \mathrm{N}_{2}\left(\mathrm{a}^{1} \pi_{\mathrm{g}}, v^{\prime \prime}\right)+\mathrm{e}^{-} & (\Delta \mathrm{E} 2-3 \mathrm{eV}) \\
\mathrm{e}^{-}+\mathrm{N}_{2}\left(\mathrm{~A}^{3} \Sigma_{\mathrm{u}}^{+}, v^{\prime}\right) \rightarrow \mathrm{N}_{2}\left(\mathrm{C}^{3} \pi_{\mathrm{u}}, v^{\prime \prime}\right)+\mathrm{e}^{-} & (\Delta \mathrm{E} 5-6 \mathrm{eV})
\end{aligned}
$$

- The ionization from the metastable state $\mathrm{N}_{2}\left(\mathrm{~A}^{3} \Sigma_{\mathrm{u}}^{+}, v^{\prime}\right)$ :

$$
\begin{gathered}
\mathrm{e}^{-}+\mathrm{N}_{2}\left(\mathrm{~A}^{3} \Sigma_{\mathrm{u}}^{+}, v^{\prime}\right) \rightarrow \mathrm{N}_{2}^{+}\left(\mathrm{X}^{2} \Sigma_{\mathrm{g}}^{+}, v^{\prime \prime}\right)+2 \mathrm{e}^{-} \quad(\Delta \mathrm{E} 9.5 \mathrm{eV}) \\
\mathrm{e}^{-}+\mathrm{N}_{2}\left(\mathrm{~A}^{3} \Sigma_{\mathrm{u}}^{+}, v^{\prime}\right) \rightarrow \mathrm{N}_{2}^{+}\left(\mathrm{B}^{2} \Sigma_{\mathrm{u}}^{+}, v^{\prime \prime}\right)+2 \mathrm{e}^{-} \quad(\Delta \mathrm{E} 13 \mathrm{eV}) \\
\mathrm{e}^{-}+\mathrm{N}_{2}\left(\mathrm{~A}^{3} \Sigma_{\mathrm{u}}^{+}, v^{\prime}\right) \rightarrow \mathrm{N}_{2}^{+}\left(\mathrm{C}^{2} \Sigma_{\mathrm{u}}^{+}, v^{\prime \prime}\right)+2 \mathrm{e}^{-} \quad(\Delta \mathrm{E} 17.5 \mathrm{eV})
\end{gathered}
$$

- The electron-ion dissociative recombination can give excited states by the ensuing reaction:

$$
\mathrm{e}^{-}+\mathrm{N}_{2}^{+}\left(\mathrm{X}^{2} \Sigma_{\mathrm{g}}^{+}, v^{\prime}\right) \rightarrow \mathrm{N}+\mathrm{N}
$$

During and after the discharge, the molecular states which are populated in the highest levels de-excite either by spontaneous emission or either by collisions.

The ion radiative transition $\mathrm{N}_{2}^{+}\left(\mathrm{B}^{2} \Sigma_{\mathrm{u}}^{+}\right)$, is done by a correlated emission to the first negative system of $\mathrm{N}_{2}$ (emission observed in our case at $391.44 \mathrm{~nm}$ ), according to the following reaction:

$$
\mathrm{N}_{2}^{+}\left(\mathrm{B}^{2} \Sigma_{\mathrm{u}}^{+}\right)_{v^{\prime}=0} \rightarrow \mathrm{N}_{2}^{+}\left(\mathrm{X}^{2} \Sigma_{\mathrm{g}}^{+}, v\right)+\mathrm{h} v_{\mathrm{FNS}}
$$

The $\mathrm{N}_{2}^{+}$ion may vanish by three-body collision to produce the polyatomic ion $\mathrm{N}_{4}^{+}$:

$$
\mathrm{N}_{2}^{+}+\mathrm{N}_{2}+\mathrm{N}_{2} \rightarrow \mathrm{N}_{4}^{+}+\mathrm{N}_{2}
$$

Or by electronic recombination [31] [32]:

$$
\begin{gathered}
\mathrm{N}_{2}^{+}+\mathrm{e} \rightarrow \mathrm{N}+\mathrm{N} \\
\mathrm{N}_{2}^{+}+\mathrm{e} \rightarrow \mathrm{N}+\mathrm{N}\left({ }^{2} \mathrm{D}\right)
\end{gathered}
$$

The $\mathrm{N}_{4}^{+}$dissociation may be done by several pathways and more particularly by recombination:

$$
\mathrm{N}_{4}^{+}+\mathrm{e} \rightarrow \mathrm{N}_{2}+\mathrm{N}_{2}
$$

The molecular state $\mathrm{N}_{2}\left(\mathrm{C}^{3} \pi_{\mathrm{u}}\right)$ de-excites to the molecular state $\mathrm{N}_{2}\left(\mathrm{~B}^{3} \pi_{\mathrm{g}}\right)$, giving the observed emissions of the nitrogen second positive system as follows [33]:

$$
\mathrm{N}_{2}\left(\mathrm{C}^{3} \pi_{\mathrm{u}}, v\right) \rightarrow \mathrm{N}_{2}\left(\mathrm{~B}^{2} \pi_{\mathrm{g}}, v^{\prime}\right)+\mathrm{h} v_{\mathrm{SPS}}
$$

With a more intense emission at $337 \mathrm{~nm}$ (Figure 9).

The state $\mathrm{N}_{2}\left(\mathrm{~B}^{3} \pi_{\mathrm{g}}, v^{\prime}\right)$ may vanish by the radiative emission of nitrogen first positive system to give the metastable $\mathrm{N}_{2}\left(\mathrm{~A}^{3} \Sigma_{\mathrm{u}}^{+}\right)$[33]. This system which created between $503 \mathrm{~nm}$ and $1051 \mathrm{~nm}$ is not underlined in our case.

$$
\mathrm{N}_{2}\left(\mathrm{~B}^{3} \pi_{\mathrm{g}}, v^{\prime}\right) \rightarrow \mathrm{N}_{2}\left(\mathrm{~A}^{3} \Sigma_{\mathrm{u}}^{+}, v^{\prime \prime}\right)+\mathrm{h} v_{\mathrm{FPS}}
$$


Or by collision with $\mathrm{N}_{2}\left(\mathrm{X}^{1} \Sigma_{\mathrm{g}}^{+}\right)$molecule, to give the $\mathrm{N}_{2}\left(\mathrm{~A}^{3} \Sigma_{\mathrm{u}}^{+}\right)$metastable state:

$$
\mathrm{N}_{2}\left(\mathrm{~B}^{3} \pi_{\mathrm{g}}\right)+\mathrm{N}_{2}\left(\mathrm{X}^{1} \Sigma_{\mathrm{g}}^{+}\right) \rightarrow \mathrm{N}_{2}\left(\mathrm{~A}^{3} \Sigma_{\mathrm{u}}^{+}\right)+\mathrm{N}_{2}\left(\mathrm{X}^{1} \Sigma_{\mathrm{g}}^{+}\right)
$$

The metastable $\mathrm{N}_{2}\left(\mathrm{~A}^{3} \Sigma_{\mathrm{u}}^{+}\right)$, may disappear by electronic collision as shown before, or by two-body collision, which by energy transfer gives the state $\mathrm{N}_{2}\left(\mathrm{C}^{3} \pi_{\mathrm{u}}, \omega^{\prime}\right)$ :

$$
N_{2}\left(A^{3} \Sigma_{u}^{+}, \omega\right)+N_{2}\left(A^{3} \Sigma_{u}^{+}, v\right) \rightarrow N_{2}\left(C^{3} \pi_{u}, \omega^{\prime}\right)+N_{2}\left(X^{1} \Sigma_{g}^{+}, v^{\prime}\right) \quad \text { R22 }
$$

The emissions between $200 \mathrm{~nm}$ and $300 \mathrm{~nm}$, are attribuated to the $\mathrm{NO}_{p}$ even if the purity degree, of the nitrogen used is $99.999 \%$, the possible ways of NO formation are [34]:

$$
\begin{gathered}
\mathrm{N}_{2}\left(\mathrm{~A}^{3} \Sigma_{\mathrm{u}}^{+}\right)+\mathrm{O}\left({ }^{3} \mathrm{P}\right) \rightarrow \mathrm{NO}\left(\mathrm{X}^{2} \Pi\right)+\mathrm{N}\left({ }^{2} \mathrm{D}\right) \\
\mathrm{N}_{2}\left(\mathrm{X}^{1} \Sigma_{\mathrm{g}}^{+}, v \geq 13\right)+\mathrm{O}\left({ }^{3} \mathrm{P}\right) \rightarrow \mathrm{NO}\left(\mathrm{X}^{2} \Pi\right)+\mathrm{N}\left({ }^{4} \mathrm{~S}\right) \\
\mathrm{N}\left({ }^{4} \mathrm{~S}\right)+\mathrm{O}_{2}(\mathrm{X}, \mathrm{v}=0) \rightarrow \mathrm{NO}\left(\mathrm{X}^{2} \Pi\right)+\mathrm{O} \\
\mathrm{N}+\mathrm{O}_{2}\left(\mathrm{a}^{1} \Delta \mathrm{g}\right) \rightarrow \mathrm{NO}\left(\mathrm{X}^{2} \Pi\right)+\mathrm{O} \\
\mathrm{N}\left({ }^{4} \mathrm{~S}\right)+\mathrm{O}+\mathrm{N}_{2} \rightarrow \mathrm{NO}\left(\mathrm{X}^{2} \Pi\right)+\mathrm{N}_{2} \\
\mathrm{~N}\left({ }^{4} \mathrm{~S}\right)+\mathrm{O}+\mathrm{O}_{2} \rightarrow \mathrm{NO}\left(\mathrm{X}^{2} \Pi\right)+\mathrm{O}_{2}
\end{gathered}
$$

Then the radiative state $\mathrm{NO}\left(\mathrm{A}^{2} \Sigma^{+}\right)$, can be formed from the ground level $\mathrm{NO}\left(\mathrm{X}^{2} \Pi\right)$ by electronic impact [35] [36] [37] or by impact with the $\mathrm{N}_{2}$ metastable state $\mathrm{N}_{2}\left(\mathrm{~A}^{3} \Sigma_{\mathrm{u}}^{+}, \omega\right)$ :

$$
\begin{gathered}
\mathrm{NO}\left(\mathrm{X}^{2} \Pi, v\right)+\mathrm{e}^{-} \rightarrow \mathrm{NO}\left(\mathrm{A}^{2} \Sigma^{+}, \omega\right)+\mathrm{e}^{-} \quad(\Delta \mathrm{E} 5.5 \mathrm{eV}) \\
\mathrm{NO}\left(\mathrm{X}^{2} \Pi, v\right)+\mathrm{N}_{2}\left(\mathrm{~A}^{3} \Sigma_{\mathrm{u}}^{+}, \omega\right) \rightarrow \mathrm{NO}\left(\mathrm{A}^{2} \Sigma^{+}, v^{\prime}\right)+\mathrm{N}_{2}\left(\mathrm{X}^{1} \Sigma_{\mathrm{g}}^{+}, \omega^{\prime}\right)
\end{gathered}
$$

$\mathrm{NO}\left(\mathrm{A}^{2} \Sigma^{+}\right)$which has a lifetime of $220 \mathrm{~ns}$ [38], can then either deexcites radiatively as:

$$
\mathrm{NO}\left(\mathrm{A}^{2} \Sigma^{+}\right) \rightarrow \mathrm{NO}\left(\mathrm{X}^{2} \Pi\right)+\mathrm{h} \mathrm{NO}_{\gamma}
$$

Or disappears by collision (quenching) as follows:

$$
\begin{array}{llll}
\mathrm{NO}\left(\mathrm{A}^{2} \Sigma^{+}\right)+\mathrm{O}_{2} \rightarrow \mathrm{NO}\left(\mathrm{X}^{2} \Pi\right)+\mathrm{O}_{2} & \text { reaction rate: } 10^{-10} \mathrm{~cm}^{3} / \mathrm{s} & \mathrm{R} 32 \\
\mathrm{NO}\left(\mathrm{A}^{2} \Sigma^{+}\right)+\mathrm{N}_{2} \rightarrow \mathrm{NO}\left(\mathrm{X}^{2} \Pi\right)+\mathrm{N}_{2} & \text { reaction rate: } 10^{-13} \mathrm{~cm}^{3} / \mathrm{s} & \mathrm{R} 33 \\
\mathrm{NO}\left(\mathrm{A}^{2} \Sigma^{+}\right)+\mathrm{NO} \rightarrow \mathrm{NO}\left(\mathrm{X}^{2} \Pi\right)+\mathrm{NO} \text { reaction rate: } 10^{-10} \mathrm{~cm}^{3} / \mathrm{s} & \mathrm{R} 34
\end{array}
$$

When the molecular oxygen is present at the impurity state with only a few tens of ppm, the quenching reaction R32 performs a marginal role in the disappearance of the radiative state $\mathrm{NO}\left(\mathrm{A}^{2} \Sigma^{+}\right)$by non-radiative collision. So it's a radiative emission R31 which prevails and allows seeing the experimentally observed spectrum in the pure nitrogen case. It is important to emphasize that the two other quenching reactions R33and R34 have a similar weight to that of $\mathrm{O}_{2}$ R32, i.e. negligible in the quenching of $\mathrm{NO}\left(\mathrm{A}^{2} \Sigma^{+}\right)$, because even if the density of the $\mathrm{N}_{2}$ carrier gas is dominant, the reaction coefficient is 1000 times smaller 
than, for instance, the reactions R32 and R34. This is what explains the negligible weight of the quenching by collision with $\mathrm{N}_{2}$ or $\mathrm{NO}$ because in addition, $\mathrm{NO}$ density is a about few tens ppm because we work in the weakly-ionized gas conditions having a low ionization and excitation degrees (less than $10^{-5}$ ) [39].

\section{Conclusions}

This work, presents the results of electrical and spectroscopic analysis of point to plane configuration corona discharge at atmospheric pressure in pure nitrogen in the pulsed applied voltage case. The variation of the inter electrode distance and the pulsed applied voltage, show that corona discharges current, average discharge current and the average propagation velocity of streamer, decreases when the inter electrode distance raises. Inversely, these values increase with the applied voltage because it is linked to the electric field and the ionization efficiency which decreases with the gap space and increases with the pulsed applied voltage. We have also studied the influence of the same operating parameters on the average discharge current and we have notified that, for a given pulsed applied voltage, the average current decreases with the inter electrode distance. Inversely, for a fixed gap distance, the average current value increases when the pulsed applied voltage rises.

The measured spectra in the pulsed corona discharge case at atmospheric pressure in pure nitrogen, allowed us to determine the emission bands of nitrogen second positive system, with seven different head bands. We also identified the emission band of nitrogen first negative system mainly for the transition $(0,0)$. We have also observed the presence of much less intense emissions, corresponding to $\mathrm{NO}_{\gamma}\left(\mathrm{A}^{2} \Sigma^{+}-\mathrm{X}^{2} \Pi\right)$ system, which covers the wavelength range from $214.9 \mathrm{~nm}$ to $289.8 \mathrm{~nm}$, with eight different transition series.

\section{References}

[1] Chang, J.S., Lawless, P.A. and Yamamoto T. (1991) Corona Discharge Processes. IEEE Transactions on Plasma Science, 19, 1152. https://doi.org/10.1109/27.125038

[2] Hsiao, M.C., Merritt, B.T., Penetrante, B.M., Vogtlin, G.E. and Wallman P.H. (1995) Plasma Assisted Decomposition of Methanol and Trichloroethylene in Atmospheric Pressure Air Streamers by Electrical Discharge Processing. Journal of Applied Physics, 78, 3451. http://doi.org/10.1063/1.359976

[3] van Veldhuizen, E.M., Rutgers, W.R. and Bityurin V.A. (1996) Energy Efficiency of NO Removal by Pulsed Corona Discharges. Plasma Chemistry and Plasma Processing, 16, 227. https://doi.org/10.1007/BF01570180

[4] van Veldhuizen, E.M. (1999) Electrical Discharges for Environmental Purposes: Fundamentals and Applications. Nova Science, New York, ISBN 1-56072-743-8.

[5] Marode, E. (1975) The Mechanism of Spark Breakdown in Air at Atmospheric Pressure between a Positive Point and a Plane. I. Experimental: Nature of the Streamer Track. Journal of Applied Physics, 46, 2005. http://doi.org/10.1063/1.321882

[6] Abahazem, A., Merbahi, N., Ducasse, O., Eichwald, O. and Yousfi, M. (2008) Primary and Secondary Streamer Dynamics in Pulsed Positive Corona Discharges. 
IEEE Transactions on Plasma Science, 36, 924. https://doi.org/10.1109/TPS.2008.925708

[7] Toyota, H., Zama, S., Akarine, Y., Matsuoka, S. and Hidaka, K. (2002) Gaseous Electrical Discharge Characteristics in Air and Nitrogen at Cryogenic Temperature. IEEE Transactions on Dielectrics and Electrical Insulation, 9, 891-898. https://doi.org/10.1109/TDEI.2002.1115482

[8] Miller, C.G. and Loeb, L.B. (1951) Positive Coaxial Cylindrical Corona Discharges in Pure $\mathrm{N}_{2}, \mathrm{O}_{2}$, and Mixtures Thereof. Journal of Applied Physics, 22, 494-503. http://doi.org/10.1063/1.1699990

[9] Kawada, Y., Shamoto, S. and Hosokawa, T. (1988) Nonosecond-Pulse Breakdown of Gas-Insulated Gaps. Journal of Applied Physics, 63, 1877-1881.

http://doi.org/10.1063/1.339885

[10] Settaouti, A. and Settaouti, L. (2007) Numerical Simulation of Corona Discharge in $\mathrm{N}_{2}$. Journal of Electrostatics, 65, 625-630. https://doi.org/10.1016/j.elstat.2007.02.001

[11] Cernak, M., Hosokawa, T., Kobayachi, S. and Kaneda, T. (1998) Streamer Mechanism for Negative Corona Current Pulses. Journal of Applied Physics, 83, 5678-5690. https://doi.org/10.1063/1.367422

[12] Mraihi, A., Merbahi, N., Yousfi, M., Abahazem, A. and Eichwald, O. (2011) Electrical and Spectroscopic Analysis of Mono- and Multi-Tip Pulsed Corona Discharges in Air at Atmospheric Pressure. Plasma Sources Science and Technology, 20, Article ID: 065002. https://doi.org/10.1088/0963-0252/20/6/065002

[13] Dubois, D., Merbahi, N., Eichwald, O., Yousfi, M. and Benhenni, M. (2007) Electrical Analysis of Positive Corona Discharge in Air and $\mathrm{N}_{2}, \mathrm{O}_{2}$, and $\mathrm{CO}_{2}$ Mixtures. Journal of Applied Physics, 101, Article ID: 053304. https://doi.org/10.1063/1.2464191

[14] Abahazem, A., Guedah, H., Merbahi, N., Yousfi, M., Eichwald, O. and Ihlal, A. (2015) Energy Injected in Multi-Tip Pulsed Corona Discharge Reactor in Air at Atmospheric Pressure for Pollution Control. Materials Today: Proceedings, 2, 46944700. https://doi.org/10.1016/j.matpr.2015.10.001

[15] Czapka, T. and Kacprzyk, R. (2011) Non-Thermal Plasma Reactor with Back Corona Discharge Electrode. Journal of Physics: Conference Series, 301, Article ID: 012019. https://doi.org/10.1088/1742-6596/301/1/012019

[16] Lan, G., Vernon, C., Rajeev, T. and Viktor, S. (1997) Study of Cathode-Directed Positive Streamers in Air by Streamer Current and Luminosity Measurements. IEEE Annual Report-Conference on Electrical Insulation and Dielectric Phenomena, Minneapolis, 19-22 October 1997, 587-590. https://doi.org/10.1109/ceidp.1997.641142

[17] Won, J.Y. and Williams, P.F. (2002) Experimental Study of Streamers in Pure $\mathrm{N}_{2}$ and $\mathrm{N}_{2} / \mathrm{O}_{2}$ Mixtures and $\mathrm{a} \approx 13 \mathrm{~cm}$ Gap. Journal of Physics $D$ : Applied Physics, 35, 205-218. https://doi.org/10.1088/0022-3727/35/3/308

[18] Wagner, K.H. (1966) Die Entwicklung der Elektronenlawine in den Plasmakanal, Untersucht mit Bildverstarker und Wischverschu $\beta$. Zeitschrift für Physik, 189, 465515. https://doi.org/10.1007/BF01338655

[19] Merbahi, N., Abahazem, A., Dubois, D., Eichwald, O. and Yousfi, M. (2008) Optical and Electrical Analyses of DC Positive Corona Discharge in $\mathrm{N}_{2} / \mathrm{O}_{2} / \mathrm{CO}_{2}$ Gas Mixtures. The European Physical Journal Applied Physics, 42, 55-61. https://doi.org/10.1051/epjap:2008035

[20] Sigmond, R.S. (1984) The Residual Streamer Channel: Return Strokes and Second- 
ary Streamers. Journal of Applied Physics, 56, 1355-1370.

https://doi.org/10.1063/1.334126

[21] Dougal, R.A. and Williams, P.F. (1984) Fundamental Processes in Laser-Triggered Electrical Breakdown of Gases. Journal of Physics D: Applied Physics, 17, 903. https://doi.org/10.1088/0022-3727/17/5/007

[22] Wagner, K.H. (1967) Vorstadium des Funkens untersucht mit Bildverstärker. Zeitschrift für Physik, 204, 177-197. https://doi.org/10.1007/BF01326133

[23] Peterkin, F.E. and Williams, P.F. (1989) Triggering in Trigatron Spark Gaps: A Fundamental Study. Journal of Applied Physics, 66, 4163.

https://doi.org/10.1063/1.344001

[24] Yagi, I., Okada, S., Matsumoto, T., Wang, D., Namihira, T. and Takaki, K. (2011) Streamer Propagation of Nanosecond Pulse Discharge with Various Rise Times. IEEE Transactions on Plasma Sciences, 39, 2232. https://doi.org/10.1109/TPS.2011.2154386

[25] Bayle, M., Bayle, P. and Crokaert, M. (1975) The Development of Breakdown in a Homogeneous Field at High Overvoltages in Helium-Neon Mixtures and Nitrogen. Journal of Physics D, 8, 2181. https://doi.org/10.1088/0022-3727/8/18/008

[26] Chalmers, L.D., Duffy, H. and Tedford, D.J. (1972) The Mechanism of Spark Breakdown in Nitrogen, Oxygen and Sulphur Hexafluoride. Proceedings of the Royal Society $A$, 329, 171. https://doi.org/10.1098/rspa.1972.0107

[27] Stritzke, P., Sander, I. and Raether, H. (1977) Spatial and Temporal Spectroscopy of a Streamer Discharge in Nitrogen. Journal of Physics D, 10, 2285. https://doi.org/10.1088/0022-3727/10/16/019

[28] Naidis, G.V. (2009) Positive and Negative Streamers in Air: Velocity-Diameter Relation. Physical Review E, 79, Article ID: 057401. https://doi.org/10.1103/PhysRevE.79.057401

[29] Komuro, A., Ono, R. and Oda, T. (2013) Effects of Pulse Voltage Rise Rate on Velocity, Diameter and Radical Production of an Atmospheric-Pressure Streamer Discharge. Plasma Sources Science and Technology, 22, Article ID: 045002. https://doi.org/10.1088/0963-0252/22/4/045002

[30] Potamianou, S., Spyrou, N., Held, B. and Loiseau, J.F. (2006) Numerical Study of Active Particles Creation and Evolution in a Nitrogen Point-to-Plane Afterglow Discharge at low Pressure. Journal of Physics D: Applied Physics, 39, 4001-4009. https://doi.org/10.1088/0022-3727/39/18/012

[31] Smith, K. and Thomson, R.M. (1978) Computer Modeling of Gas Lasers. Plenum Press, New York, 416. https://doi.org/10.1007/978-1-4757-0641-3

[32] Bortner, M.H. and Baurer, T. (1978) DNA. 2nd Edition, 1948H, TEMPO 24, General Electric, Boston.

[33] Zerrouki, A., Motomura, H., Ikeda, Y., Jinno, M. and Yousfi, M. (2016) Optical Emission Spectroscopy Characterizations of Micro-Air Plasma Used for Simulation of Cell Membrane Poration. Plasma Physics and Controlled Fusion, 58, Article ID: 075006. https://doi.org/10.1088/0741-3335/58/7/075006

[34] Pintassilgo, C.D., Loureiro, J. and Guerra, V. (2005) Modeling of a $\mathrm{N}_{2}-\mathrm{O}_{2}$ Flowing Afterglow for Plasma Sterilization. Journal of Physics D: Applied Physics, 38, $417-$ 430. https://doi.org/10.1088/0022-3727/38/3/011

[35] Simek, M., Babicky, V., Clupek, M., DeBenedictis, S., Dilecce, G. and Sunka, P. (1998) Excitation of $\mathrm{N}_{2}\left(\mathrm{C}^{3} \pi_{\mathrm{u}}\right)$ and $\mathrm{NO}\left(\mathrm{A}^{2} \Sigma^{+}\right)$States in a Pulsed Positive Corona Discharge in $\mathrm{N}_{2}, \mathrm{~N}_{2}-\mathrm{O}_{2}$ and $\mathrm{N}_{2}-\mathrm{NO}$ Mixtures. Journal of Physics D: Applied Physics, 
31, 2591-2602. https://doi.org/10.1088/0022-3727/31/19/032

[36] Simek, M. (2002) The Modelling of Streamer-Induced Emission in Atmospheric Pressure, Pulsed Positive Corona Discharge: $\mathrm{N}_{2}$ Second Positive and NO-Y Systems. Journal of Physics D: Applied Physics, 35, 1967-1980. https://doi.org/10.1088/0022-3727/35/16/311

[37] Luque, J. and Crosely, D.R. (1999) Transition Probabilities and Electronic Transition Moments of the $\mathrm{A}^{2} \Sigma^{+}-\mathrm{X}^{2} \Pi$ and $\mathrm{D}^{2} \Sigma^{+}-\mathrm{X}^{2} \Pi$ Systems of Nitric Oxide. The Journal of Chemical Physics, 111, 7405-7415. https://doi.org/10.1063/1.480064

[38] McDermid, I.S. and Laudenslager, J.B. (1982) Radiative Lifetimes and Electronic Quenching Rate Constants for Single Photon Excited Rotational Levels of NO $\left(\mathrm{A}^{2} \Sigma^{+}, v^{\prime}=0\right)$. Journal of Quantitative Spectroscopy and Radiative Transfer, 27, 483492.

[39] Lepikhin, N.D., Klochko, A.V., Popov, N.A. and Starikovskaia, S.M. (2016) LongLived Plasma and Fast Quenching of $\mathrm{N}_{2}\left(\mathrm{C}^{3} \pi_{\mathrm{u}}\right)$ by Electrons in the Afterglow of a Nanosecond Capillary Discharge in Nitrogen. Plasma Sources Science and Technology, 25, Article ID: 045003. https://doi.org/10.1088/0963-0252/25/4/045003

\section{Scientific Research Publishing}

Submit or recommend next manuscript to SCIRP and we will provide best service for you:

Accepting pre-submission inquiries through Email, Facebook, LinkedIn, Twitter, etc. A wide selection of journals (inclusive of 9 subjects, more than 200 journals)

Providing 24-hour high-quality service

User-friendly online submission system

Fair and swift peer-review system

Efficient typesetting and proofreading procedure

Display of the result of downloads and visits, as well as the number of cited articles

Maximum dissemination of your research work

Submit your manuscript at: http://papersubmission.scirp.org/

Or contact jasmi@scirp.org 